\title{
Review
}

\section{Neurobiology of Acupuncture: Toward CAM}

\author{
Sheng-Xing Ma
}

\begin{abstract}
Departments of Obstetrics and Gynecology, Harbor-UCLA Medical Center, David Geffen School of Medicine at University of California at Los Angeles, Torrance, CA, USA
\end{abstract}

\begin{abstract}
It has long been accepted that acupuncture, puncturing and scraping needles at certain points on the body, can have analgesic and anesthetic effects, as well as therapeutic effects in the treatment of various diseases. This therapy, including acupuncture anesthesia, has drawn the attention of many investigators and become a research subject of international interest around the world. Numerous studies have demonstrated that the nervous system, neurotransmitters, endogenous substances and Jingluo (meridians) may respond to needling stimulation and electrical acupuncture. An abundance of information has now accumulated concerning the neurobiological mechanisms of acupuncture, in relation to both neural pathways and neurotransmitters/hormonal factors that mediate autonomic regulation, pain relief and other therapeutics. Early studies demonstrated that the analgesic effects of electroacupuncture (EA) are mediated by opioid peptides in the periaqueductal gray. Recent evidence shows that nitric oxide plays an important role in mediating the cardiovascular responses to EA stimulation through the gracile nucleus-thalamic pathway. Other substances, including serotonin, catecholamines, inorganic chemicals and amino acids such as glutamate and $\alpha$-aminobutyric acid (GABA), are proposed to mediate certain cardiovascular and analgesic effects of acupuncture, but at present their role is poorly understood. The increased interest in acupuncture health care has led to an ever-growing number of investigators pursuing research in the processes of the sense of needling touch, transduction of needling stimulation signals, stimulation parameters and placebos. In this Review, the evidence and understanding of the neurobiological processes of acupuncture research have been summarized with an emphasis on recent developments of nitric oxide mediating acupuncture signals through the dorsal medulla-thalamic pathways.
\end{abstract}

Keywords: acupuncture - neurobiology - neurotransmitter - nitric oxide - opiate - pain

\section{CAM Approaches to Acupuncture}

Over the last few decades there has been a widespread and increasing interest in acupuncture around the world. Investigators have demonstrated that the nervous system, neurotransmitters and endogenous substances respond to needling stimulation and electroacupuncture (EA) (1-3). The EA afferent pathways and central sites have been identified in the anterolateral tract in the spinal cord, the reticulogigantocellular nucleus, the raphe magnus, the dorsal part of the periaqueductal central gray (D-PAG), the posterior and anterior hypothalamus and the medial part of the centromedian nucleus of the thalamus (4-7). It has been established that acupuncture analgesia is mediated by opioid peptides.

For reprints and all correspondence: Department of Obstetrics and Gynecology, Harbor-UCLA Medical Center, David Geffen School of Medicine at University of California at Los Angeles, 1124 W. Carson Street, RB-1, Torrance, CA 90502, USA. E-mail: ma@humc.edu
Recent studies have demonstrated that EA stimulation of hindlimb acupoints induces an up-regulation of neuronal nitric oxide synthase (nNOS)/NADPH diaphorase (NADPHd) expression in the gracile nucleus. Nitric oxide (NO) in the gracile nucleus mediates acupuncture signals through dorsal medulla-thalamic pathways.

\section{Opioidergic Mechanism in the Periaqueductal Central Gray}

Several reports from 1977 to 1980 demonstrated that acupuncture analgesia is blocked or reversed by naloxone, an opioid antagonist (8-10). It has also been shown that intracerebroventricular or intrathecal injection of cholecystokinin octapeptide (CCK-8), an endogenous opioid antagonist, blocks analgesia induced by morphine or EA in rats (11), indicating that an opioidergic mechanism is involved in mediating acupuncture analgesia. These reports have shown that naloxone reduces or abolishes the analgesia produced by 
manual rotation of needles or low-frequency EA in human subjects with experimental or chronic pain (12). Furthermore, naloxone reduced or abolished low-frequency EA analgesia in various animals subjected to pain $(8,10,11)$. Investigators have also demonstrated that a microinjection of naloxone into the periaqueductal gray matter and the hypothalamus abolishes the analgesic effects of acupuncture in animals $(1,4)$. These studies not only confirm that lowfrequency EA analgesia is naloxone reversible, but also show the regions of the brain involved in mediating acupuncture analgesia.

Several studies have observed that acupuncture and transcutaneous nerve stimulation has a prolonged induction and delayed recovery period (13-15). Low frequency stimulation of the somatic nerve also produces selective and long-lasting depression of the vasoconstrictor components of the midbrain-evoked cardiovascular defense response (16). It has been demonstrated that the antinociceptive effects induced by EA twice in succession are markedly enhanced in the second EA at 90 min following the first EA. The first EA effect is opioid-mediated in the periaqueductal gray and the second response to EA is a non-opioid effect (17). The sympathoinhibition and analgesia induced by low-frequency transcutaneous nerve stimulation is not antagonized by naloxone, an opioid-receptor-blocking drug $(14,15)$. The neural pathways and neurotransmitters responsible for the non-opioid effects of EA (the long-induction time and the long-lasting effects of acupuncture) are unknown.

\section{Nitric Oxide in the Dorsal Medulla-Thalamic Pathways}

It has been demonstrated that NADPHd reactivity in the gracile nucleus is markedly increased in intact aged rats and is induced following sciatic nerve axotomy in young rats, accompanied by increased number of cells showing expression of nNOS proteins and mRNA $(18,19)$. nNOS catalyzes the transformation of arginine to NO, which is an endogenous molecule produced in many cell types including neurons in the brain $(20,21)$. It has been shown that NADPHd reactivity and nNOS immunoreactivity are increased in the gracile nucleus induced by either unilateral electrical stimulation of the sural nerve or by sciatic nerve injury $(19,22)$. These studies support the previous findings that the gracile nucleus receives somatosympathetic afferent inputs and demonstrate an increase in nNOS expression in the gracile nucleus with an ipsilateral predominance induced by activation of afferent somatic cutaneous nerves. Furthermore, they reported that low-frequency EA stimulation $(3 \mathrm{~Hz})$ applied to the hindlimb acupuncture points (acupoints) Jinggu and Shugu (BL 64-65), which are cutaneously located, induces nNOS expression in the gracile nucleus (23). Although the functional purpose for the transganglionic and/or transsynaptic up-regulation of nNOS in the gracile nucleus requires investigation, the results suggest that EA-induced nNOS-NO in the gracile nucleus may participate in central autonomic

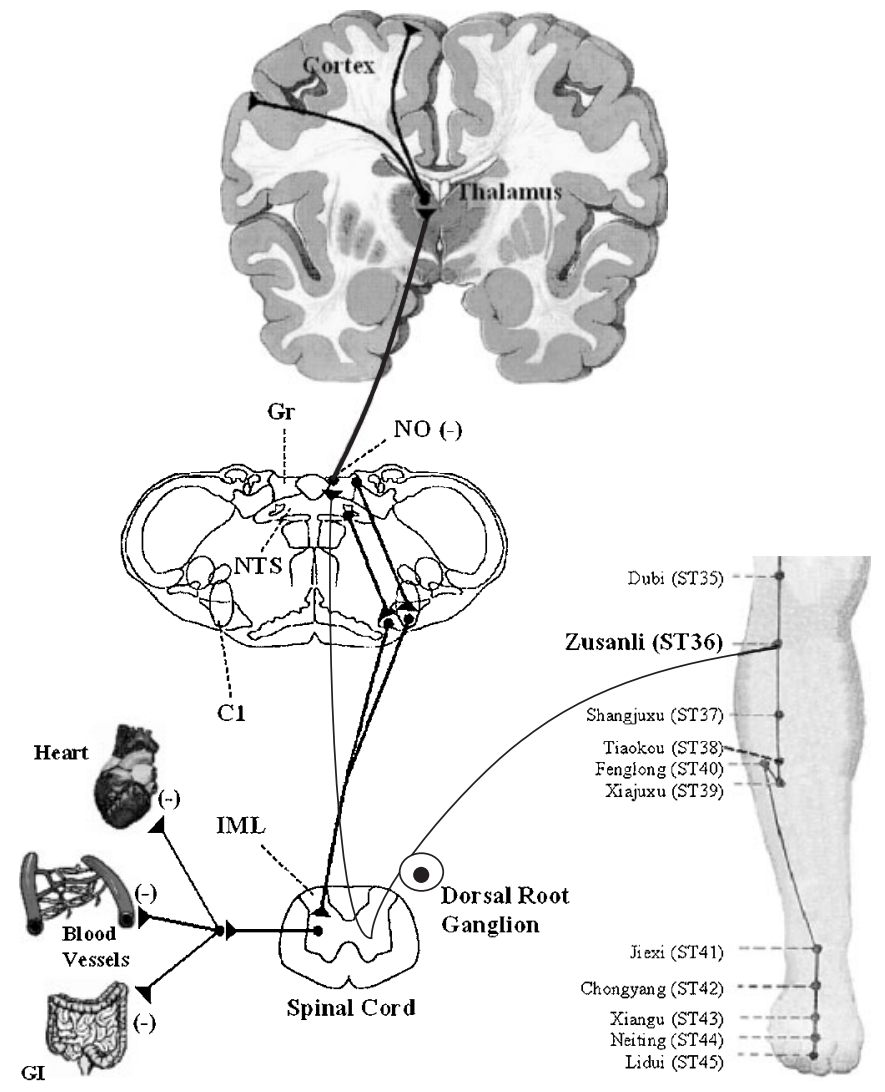

Figure 1. Neural circuits related to somatosympathetic reflexes in the gracile-thalamic-cortex pathways. Axonal tracing studies show that cutaneous primary afferents projecting from the hindlimb to the medulla are distributed mainly in the gracile nucleus, and synapses from the gracile nucleus, which receive somatosensory afferent inputs project to the thalamus. Acupuncture stimulation of hindlimb, similar to electrical stimulus to the tibial nerve causes NO-mediated activation of somatosympathetic reflexes in this pathway resulting in sympathoinhibition and analgesia.

regulation of somatosympathetic reflex (SSR) activities, which contribute to the therapeutic effects of acupuncture.

As illustrated in Fig. 1, the somatotopic organization of the gracile nucleus receiving peripheral somatosensory afferents from the hindlimb has been demonstrated with electrophysiological mapping studies and anterograde axons tracing techniques in various mammals (24-26). The gracile nucleus in the dorsal medulla receives peripheral somatosensory nociceptive afferents projecting from the hindlimb $(25,26)$, and activation of afferent cutaneous nerves results in changes in sympathetic activity and arterial blood pressure by excitatory SSR $(27,28)$. It has been shown that cutaneous primary afferents projecting from the hindlimb to the medulla oblongata are distributed mainly in the gracile nucleus $(24,26)$. The afferent sensory fibers in the sciatic nerves originate from the skin or muscle and the synapse is directed on dorsal horn neurons, or on dorsal horn interneurons in the spinal cord, which ascend to the gracile nucleus $(24-26,29)$. Early studies have shown that neurons in the gracile nucleus, which receive somatosensory afferent inputs originating in nociceptors, project to the thalamus $(25,30)$. A number of recent studies 

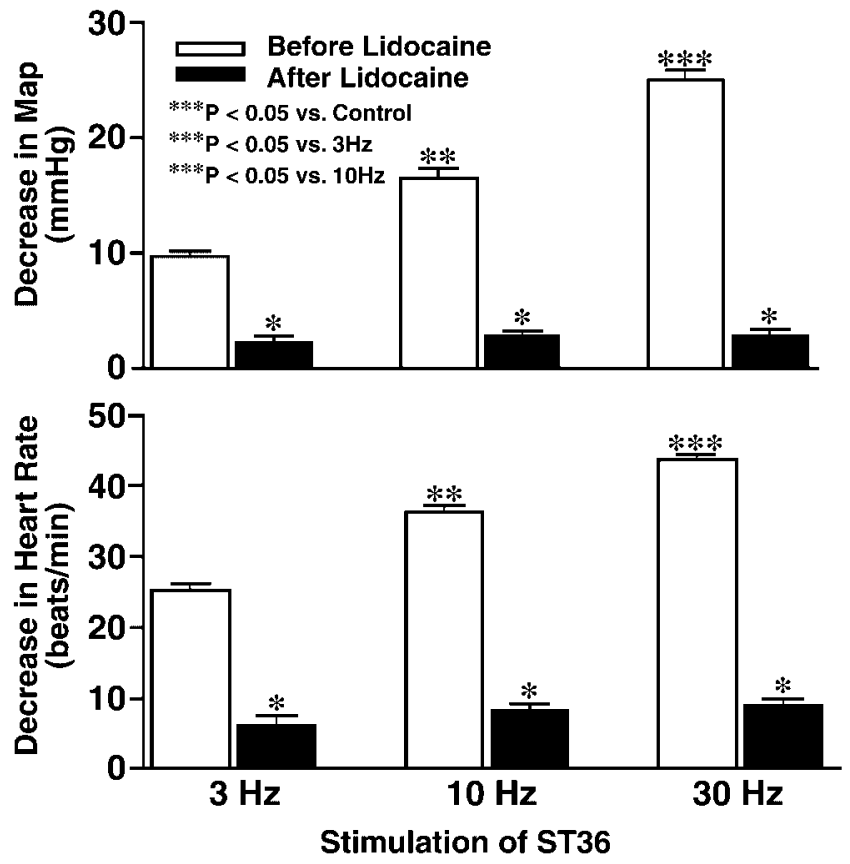

Figure 2. Frequency-dependent changes in mean arterial pressure (MAP, top) and heart rate (bottom) induced by EA ST36 in anesthetized SpragueDawley rats. Hypotensive and bradycardiac responses to EA stimulation of ST36 were significantly blocked by microinjection of lidocaine into gracile nucleus ( $P<0.05$, analysis of variance, $n=7 /$ group). Parameters of stimulation: $6 \mathrm{~V}, 1 \mathrm{~ms}$ pulse duration, 3,10 and $30 \mathrm{~Hz}$ for $10 \mathrm{~s}$. [Reproduced with permission from Chen and Ma (44).]

have suggested that the gracile nucleus is an integration center for cutaneous and visceral information flowing into the thalamus, which plays an important role in somatic and visceral pain processing (31-33). Electrophysiological studies have identified that the somatosensory afferent inputs ascend in the paraventricular thalamic nucleus (PVT), and adjacent thalamic nuclei $(34,35)$. The PVT with the mediodorsal thalamic nucleus plays a role in the central autonomic control of cardiovascular and other integrative functions $(36,37)$.

It has been reported that stimulation of afferent somatic cutaneous or mixed nerves, such as the sural or the sciatic, results in increased sympathetic activity and arterial blood pressure by excitatory SSR $(27,28)$. Early studies have suggested that synaptic transmission through the dorsal column is depressed by $\alpha$-aminobutyric acid (GABA)-mediated depolarization of the gracile afferents evoked by stimulation of the dorsal column $(38,39)$. Investigators have shown that NO in the brainstem produces baroreflex-independent inhibition of sympathetic tone and thus decreases arterial blood pressure $(40,41)$; NO in the brainstem possesses an inhibitory function in the central regulation of somatocardiac sympathetic C-reflex (42). Recent studies have shown that $\mathrm{L}$-arginine-derived NO synthesis in the gracile nucleus attenuates the cardiovascular responses to stimulus-evoked excitatory SSR and facilitates the responses to inhibitory SSR (43). We hypothesize that $\mathrm{NO}$ in the gracile nucleus plays an

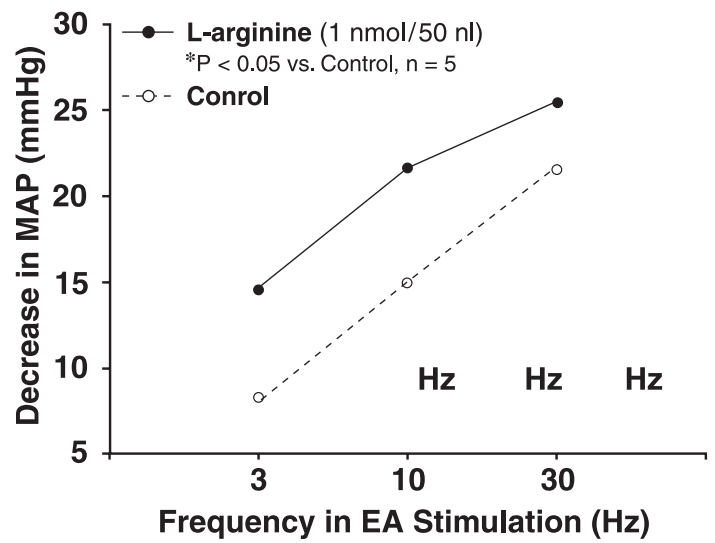

Figure 3. Frequency-response curves for changes in mean arterial blood pressure (MAP) in responses to EA stimulation of ST36 before and after microinjection of L-arginine into the gracile nucleus in anesthetized rats. Microinjection of L-arginine into the gracile nucleus enhanced the depressor and bradycardiac responses to EA ST36 $(P<0.05$, analysis of variance, $n=$ 5 /group). Other details are shown in legend to figure 2 . [Reproduced with permission from Chen and Ma (44).]

inhibitory role in central cardiovascular control through SSR regulation (Fig. 1).

Chen and Ma (44) have studied the effects of L-argininederived NO synthesis in the gracile nucleus on the cardiovascular responses to EA stimulation of 'Zusanli (ST36)'. EA stimulation of ST36 produces depressor and bradycardiac responses in rats but the same stimulation on the non-points caused slight cardiovascular responses (44). Microinjections of lidocaine into the gracile nucleus blocks this response, indicating that the gracile nucleus is involved in mediating cardiovascular responses to ST36 (Fig. 2). Moreover, microinjection of L-arginine into gracile nucleus facilitated the hypotensive and bradycardiac responses to EA ST36, as shown in Fig. 3. The cardiovascular responses to EA ST36 were attenuated by bilateral microinjection of nNOS antisense oligos into gracile nucleus (Fig. 4). The results suggest that NO plays an important role in mediating the cardiovascular responses to EA ST36 through gracile nucleus. Recent results have also shown that analgesic responses to EA ST36 are modified by L-arginine-derived NO synthesis in the gracile nucleus (45). Extracellular neuronal activity in the thalamus is enhanced by EA ST36, and EA ST36evoked activity is inhibited by the presence of NO in the gracile nucleus (46). These results are consistent with previous studies showing that the thalamic neurons receive neural inputs from the gracile nucleus and further demonstrate that NO in the gracile nucleus has an inhibitory function in mediating the responses to EA ST36 by influencing the excitability of the thalamic neurons. The gracile nucleus-thalamic pathways are responsible for EA signal transduction, with NO playing an important role in the mediation of neuronal activities and therapeutics elicited by EA ST36.

There is growing evidence that the dorsal column pathway (gracile nucleus) plays an important role in pain homeostasis and nociceptive regulation (31-33). These recent reports 

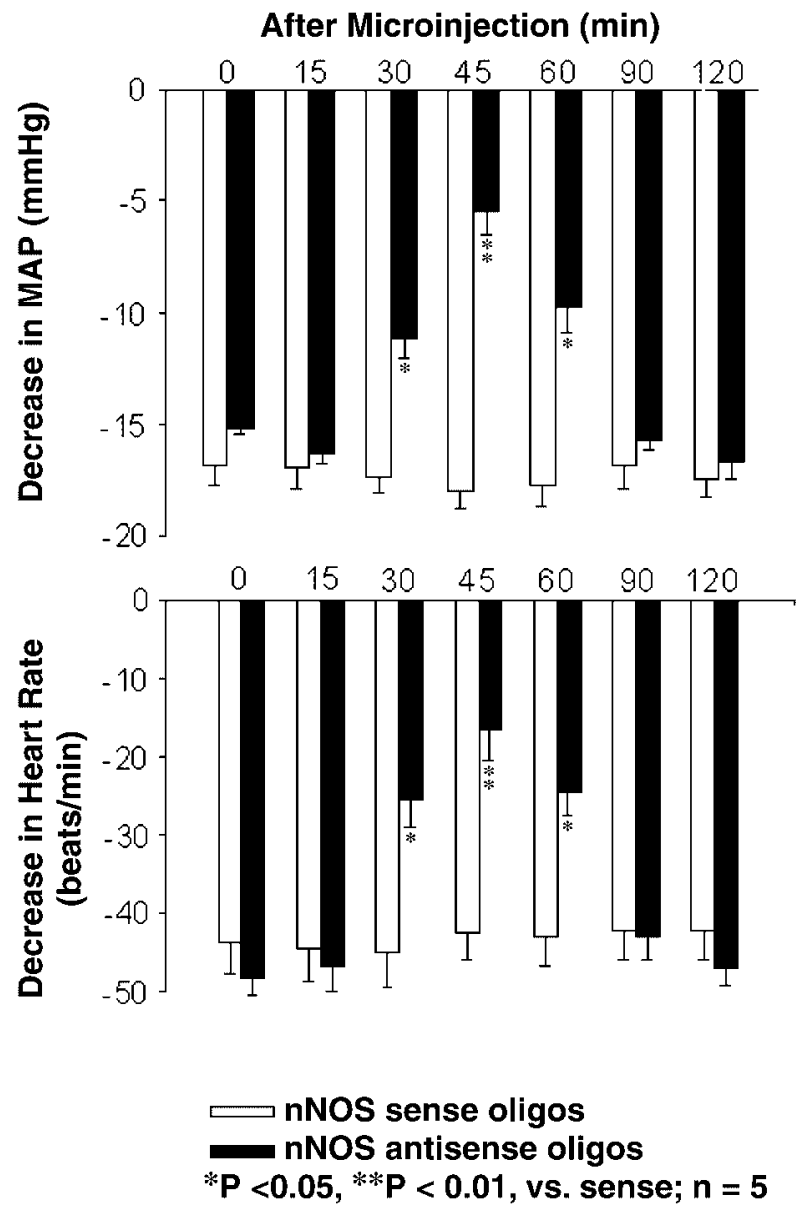

Figure 4. Time response histogram of antisense oligos to nNOS in the gracile nucleus on the cardiovascular responses caused by EA ST36 in rats. The depressor (top) and bradycardiac responses (bottom) were inhibited by microinjection of nNOS antisense oligos into the gracile nucleus $(P<0.05$, analysis of variance, $n=5$ /group). The inhibiting effects began at $30 \mathrm{~min}$ after injection, and the maximum effects occurred at $45 \mathrm{~min}$. The effects reversed at $90 \mathrm{~min}$ after the injection. Microinjection of nNOS sense oligos into the gracile nucleus did not alter the responses to stimulation of ST36. Other details are shown in legend to figure 2. [Reproduced with permission from Chen and Ma (44).]

support the results from early studies using axonal tracing, functional assays and electrophysiology, which have demonstrated a somatosensory nerves-gracile nucleus-thalamic pathway which contributes to SSR activities (24-26,29,30). Recent studies have demonstrated that NO produces inhibitory cardiovascular regulation in the brainstem (40-42), and nNOS-NO in the gracile nucleus modifies SSR functions while gracile $\mathrm{nNOS}$ is induced by sensory nerve stimulation or lesion $(18,19,43)$. EA stimulation of hindlimb acupoints consistently induces nNOS expression in the gracile nucleus, and L-arginine-derived NO synthesis in the gracile nucleus mediates cardiovascular responses to EA ST36 $(23,44)$. However, systematic studies of the effects of NO in the gracile nucleus on analgesic responses to EA stimulation of hindlimb acupoint, including studies of other brainstem nuclei such as the cuneate nucleus to serve as a site specificity control, are required to evaluate the functional roles of the dorsal column (gracile nucleus)-thalamic pathway in transduction and modification of acupuncture signals and therapeutic effects of acupuncture.

\section{The Descending Pain Modulatory System}

It is generally accepted that multiple supraspinal sites of the descending pain modulatory system exert powerful effects on the inhibitory response of the nociceptive messages at the spinal level $(47,48)$. The rostral ventromedial medulla (RVM), including the nucleus raphe magnus (NRM), the adjacent gigantocellularis pars alpha $(\mathrm{NGC} \alpha)$ and ventral nucleus reticularis gigantocellularis (NGC), plays a crucial role in descending pain modulation $(49,50)$. The NRM is a major source of the descending brainstem serotoninergic pathways and the pontine locus coeruleus/subcoeruleus (LC/ $\mathrm{SC})$ sends the descending noradrenergic projections to the spinal dorsal horn in rats (49-51). It has been demonstrated that EA inhibited Fos expression in the dorsal horn induced by mechanical noxious stimulation or hindlimb amputation $(52,53)$ and inhibited the nociceptive response (53). Recent studies have suggested that EA-activated spinal neurons convey acupuncture signals to the brain and activate a descending inhibitory system, which in turn inhibits cFos expression in the medial area of laminae I-II in spinal cord and hyperalgesia $(54,55)$.

Takeshige et al. (56), demonstrated that the paragigantocellular reticular nucleus in the descending adrenergic system is elicited by acupuncture stimulation since the inhibitory effects are antagonized by phentolamine (57). The paragigantocellular reticular nucleus does not contain any noradrenergic cells, therefore it must relay to a noradrenergic structure, the LC, or some other noradrenergic lower brainstem neurons whose axons project into the spinal cord. These researchers have also reported that acupuncture effects are antagonized by methysergide (56). These results suggest that acupuncture anesthesia descending through PAG is eventually serotonergic. Investigators have also reported that serotonin levels are increased in mast cells and platelets following acupuncture $(58,59)$. These latter reports might be considered an explanation of the long lasting effects of acupuncture in addition to direct synaptic inhibition.

\section{EA Stimulation Parameters and Placebos}

Electrical stimulation has been widely used in acupuncture research on animal models and humans because it can be controlled and quantified easily, and thus it is repeatable. The effect of EA depends on stimulation parameters, which include intensity, frequency, pulse widths (duration) and time table. 


\section{Identified Primary Afferents by Using Different EA Intensity}

The spatial organization of the central terminals of primary afferents are located in the dorsal horn: the low-threshold $\mathrm{A} \alpha / \mathrm{A} \beta$ mechanoreceptors are distributed longitudinally in laminae III-V; the high-threshold C fibers terminate longitudinally in laminae I and II; and A $\delta$ mechanoreceptors terminate in laminae I and V $(60,61)$. Examination of compound action potentials in rats shows that a stimulus of $0.1 \mathrm{~mA}$ is sufficient for producing an $A \alpha / A \beta$ wave in the dorsal root, but not $\mathrm{A} \delta$ wave, which requires at least $0.2 \mathrm{~mA}$. Production of a $\mathrm{C}$ wave requires at least $1 \mathrm{~mA}(62)$. It is generally accepted that acupuncture/EA activates deep receptors (63), and EA-evoked effects appear to be manifested via activation of small-diameter, high-threshold primary sensory afferents, possibly C fibers $(64,65)$. EA-induced activation of largediameter primary afferents alone produces analgesic and antinociceptive effects (66-69).

\section{Stimulation Frequency}

Low frequency stimulation of acupuncture points produces arterial blood depression and analgesia in rats $(13,17)$. Effects of low frequency EA are likely processed in the higher center, while high frequency EA effects are most likely located between supraspinal and the lower brainstem (4, 70-72). Low frequency EA activates beta-endorphin and enkephalin systems, while high frequency EA activates dynorphin systems (73). More recent studies have shown that high $(100 \mathrm{~Hz})$ and low $(10 \mathrm{~Hz})$ EA frequencies may induce similar antihyperalgesic effects (74).

\section{Pulse Widths (Duration) and Time Table}

Durations of $1.0 \mathrm{~ms}$ are frequently used in EA treatment in both animal studies and clinical observations. Recent studies suggest that higher EA current intensity is more effective than wider EA pulse width in enhancing antihyperalgesia at a given frequency (74). Acupuncture has a prolonged induction and a delayed recovery period $(13,17)$. The antinociceptive effects induced by EA twice in succession are markedly enhanced in the second EA at 90 min following the first EA (17). Thus, 20-30 min EA is the best stimulation period; two phases stimulation is better than single stimulation and a longer EA treatment may not necessarily correlate with a better therapeutic effect.

\section{Placebo Effects and Sham Acupuncture}

To evaluate specific effects, choosing an appropriate control is an important issue in acupuncture research. Controls applied in acupuncture research include placebo, sham acupuncture, needling superficially, needling wrong or inadequate points, etc. In the most commonly used control treatments, needling is carried out at theoretically irrelevant sites, away from the classical acupoint locations, called 'non- acupoints'. Depth of insertion and stimulation are the same, with the needle inserted close to acupoints and related meridian lines, but in an area that does not contain acupoints or meridian lines. This procedure, which is termed 'non-acupoints' or 'sham' acupuncture, has been used as a placebo in many studies (75-77). This method was initially assumed by most investigators to be ineffective, and therefore ideal for use as a control or placebo. However, many studies found that this control has some of the same effects as real acupuncture $(75,77-81)$. It is clear that this control only offers information about the most effective sites of needling, not about the specific effects of acupuncture (82).

Investigators have recently designed a sham acupuncture needle (the Park Sham Needle) which does not puncture the skin, but appears to do so from the point of view of the naive patient (83). The apparatus consists of a blunted needle, with a shaft that telescopes into the handle when applied to the surface of the skin. Although the needle appears to have been inserted, it does not actually pierce the skin. In testing the efficacy of the sham acupuncture device, research has found that the procedure using the new device is indistinguishable from the same procedure using real needles in acupuncture (84). Similar to the Park Sham Needle, the Placebo Needle was designed to simulate the acupuncture needling procedure without puncturing the skin (85). In testing this new device, results demonstrated that, of 60 volunteers, 54 felt a penetration with acupuncture and 47 felt it with the placebo needle.

As the major focus on the specific effects of acupuncture, minimal acupuncture has been used as a control condition in several studies to minimize the specific effects of the needling, while maintaining the psychological impact since it is very similar to real treatment. It is possible that minimal acupuncture might have a small therapeutic effect but it is slightly more difficult to demonstrate a difference between treatment and control (82). In some sham-treated controls, the needle electrode is placed into the same acupoints with the same depth of insertion but without performing the stimulation. A needle taped on the surface of the acupoint is also used to serve as a placebo control. There is some evidence to show that certain types of acupuncture 'placebos' may have effects (86). It appears that evidence for the effectiveness of placebo is inadequate, and somewhat controversial.

\section{Conclusion}

The utilization of acupuncture and EA therapies is high and on the rise in Western societies. Acupuncture involves stimulating specific anatomic points along the body by puncturing the skin with a needle; practitioners may also use heat, pressure or impulses of electrical energy to stimulate the points. Investigators have demonstrated that the nervous system, neurotransmitters and endogenous substances respond to needling stimulation and EA (1-3). The EA afferent pathways and central sites have been identified in the anterolateral tract in the spinal cord, the reticulogigantocellular nucleus, the raphe magnus, the dorsal part of the periaque- 
ductal central gray, the posterior and anterior hypothalamus, the medial part of the centromedian nucleus of the thalamus, and the dorsal medullar-thalamic pathways $(4-8,23,44-46)$. Prior studies have established that acupuncture analgesia is mediated by opioid peptides (8-12). Recent evidence has demonstrated that L-arginine-derived $\mathrm{NO}$ in the gracile nucleus contributes to neuronal responses to EA hindlimb acupoints through the dorsal medullar-thalamic neuronal pathway $(23,44-46)$. Other substances, including serotonin, catecholamines, inorganic chemicals and amino acids such as glutamate and GABA, may also mediate some of the cardiovascular and analgesic effects of acupuncture, but at present their role is little understood (1-3). In spite of experiments documenting a biological basis of acupuncture analgesia and the increasing use of acupuncture for a number of pain conditions, systematic research of EA manipulation and stimulation has not been conducted. Only further evidence of the neurobiology mechanisms and effectiveness of acupuncture research will answer these questions.

\section{Acknowledgments}

The author thanks Diane Guettler for manuscript editing and preparation, and Shuang Chen and Xi-yan Li for their technical assistance during the studies. This work was supported by NIH (AT00209, HL04447, AT00450 and DH36169). These studies were conducted at the biomedical research facilities of the Research and Education Institute at HarborUCLA Medical Center.

\section{References}

1. Foster JMG, Sweeney BP. The mechanisms of acupuncture analgesia. Br J Hosp Med 1987; October:38:308-12.

2. Qian XZ. Progress in scientific research on acupuncture, moxibustion and acupuncture anesthesia by integrating traditional Chinese and Western medicine. In Zhang XT. (ed.), Research on Acupuncture, Moxibustion, and Acupuncture Anesthesia. Beijing: Science Press, 1986; $1-18$.

3. Tang D. Advances of research on the mechanism of acupuncture and moxibustion. Acup Res 1987;4:278-84.

4. Wang Q, Mao LM, Han JS. The arcuate nucleus of hypothalamus mediates low but not high frequency electroacupuncture analgesia in rats. Brain Res 1990;513:60-6.

5. Takeshige C, Sato T, Komugi H. Role of peri-aqueductalcentral gray in acupuncture analgesia. Acupunct Electrother Res 1980;5:323-37.

6. Takeshige C, Oka K, Mizuno T, Hisamitsu T, Luo CP, Kobori M, et al. The acupuncture point and its connecting central pathway for producing acupuncture analgesia. Brain Res Bull 1993;30:53-67.

7. Andersson SA, Holmgren E. On acupuncture analgesia and the mechanism of pain. Am J Chin Med 1975;3:311-34.

8. Cheng RSS, Pomeranz BH. Electroacupuncture analgesia is mediated by stereospecific opiate receptors and is reversed by antagonists of type 1 receptors. Life Sci 1980;26:631-8.

9. Mayer DJ, Price DD, Raffi A. Antagonism of acupuncture analgesia in man by the narcotic antagonist naloxone. Brain Res 1977;121:368-72.

10. Sjolund BH, Eriksson MB. The influence of naloxone on analgesia produced by peripheral conditioning stimulation. Brain Res 1979;173:295302.

11. Han JS, Ding XZ, Fan SG. Cholecystokinin octapeptide (CCK-8): Antagonism to electroacupuncture analgesia and a possible role in electroacupuncture tolerance. Pain 1986;27:101-15.

12. Mayer DJ, Price DD, Raffii A. Antagonism of acupuncture analgesia in man by the narcotic antagonist naloxone. Brain Res 1977;121:368-72.
13. Ernst M, Lee MHM. Sympathetic effects of manual and electrical acupuncture of the tsusanli knee point: comparison with the hoku hand point sympathetic effects. Exp Neurol 1986;94:1-10.

14. Kaada B. Vasodilation induced by transcutaneous nerve stimulation in peripheral ischemia (Raynaud's phenomenon and diabetic polyneropathy). Eur Heart J 1982;3:303-14.

15. Kaada B, Eieben O. In search of mediators of skin vasodilation induced by transcutaneous nerve stimulation. II. Serotonin implicated. Gen Pharmacol 1983;14:635-64.

16. Lovick TA, Li P, Schenberg LC. Modulation of the cardiovascular defense response by low frequency stimulation of a deep somatic nerve in rats. J Auton Nerv Syst 1995;50:347-54.

17. Pomeranz B, Warma N. Electroacupuncture suppression of a nociceptive reflex is potentiated by two repeated electroacupuncture treatments: The first opioid effect potentiates a second non-opioid effect. Brain Res 1988;452:232-6.

18. Ma SX, Holley AT, Sandra A, Cassell MD, Abboud FM. Increased expression of nitric oxide synthase in the gracile nucleus of aged rats. Neuroscience 1997;76:659-63.

19. Ma SX, Cornford ME, Vahabnezhad I, Wei SM, Li XY. Responses of nitric oxide synthase expression in the gracile nucleus to sciatic nerve injury in young and aged rats. Brain Res 2000;855:124-31.

20. Moncada S, Higgs EA. Endogenous nitric oxide: physiology, pathology and clinical relevance. Eur J Clin Invest 1991;21:361-74.

21. Bredt DS, Snyde SH. Nitric oxide, a novel neuronal messenger. Neuron 1992;18:3-11.

22. Ma SX. Nitric oxide synthase in the gracile nucleus is increased by stimulus-evoked excitatory somato-sympathetic reflexes. FASEB J 1998;12: A691.

23. Ma SX, Li XY. Increased neuronal nitric oxide synthase expression in the gracile nucleus following electroacupuncture stimulation of cutaneous hindlimb acupoints. Acupunct Electrother Res 2002;27:157-69.

24. Gulley RL. Golgi studies of the nucleus gracilis in the rat. Anatomical Record 1973;111:325-42.

25. Leem JW, Lee BH, Willis WD, Chung JM. Grouping of somatosensory neurons in the spinal cord and the gracile nucleus of the rat by cluster analysis. J Neurophysiol 1994;72:2590-7.

26. Ueyama T, Houtani T, Ikeda M, Sato K, Sugimato T, Mizuno N. Distribution of primary afferent fibers projecting from hindlimb cutaneous nerves to the medulla oblongata in the cat and rat. J Comp Neurol 1994;341:145-58.

27. Sato A, Schmidt RF. Somatosympathetic reflexes: afferent fibers, central pathways, discharge characteristics. Physiol Rev 1973;53:916-47.

28. Samso E, Farber NE, Kampine JP, Schmeling WT. The effects of halothane on pressor and depressor responses elicited via the somatosympathetic reflex: A potential antinociceptive action. Anesth Analg 1994;79:971-9.

29. Wessels WJT, Feirabend HKP, Marani E. Development of projections of primary afferent fibers from the hindlimb to the gracile nucleus: a WGA-HRP study in the rat. Brain Res Dev Brain Res 1991;63:265-79.

30. Cliffer KD, Hasegawa T, Willis WD. Responses of neurons in the gracile nucleus of cats to innocuous and noxious stimuli: basic characterization and antidromic activation from the thalamus. J Neurophysiol 1992;68: 818-32.

31. Al-Chaer ED, Lawand NB, Westlund KN, Willis WD. Visceral nociceptive input into the ventral posterolateral nucleus of the thalamus: a new function for the dorsal column pathway. J Neurophysiol 1996;76:266174.

32. Al-Chaer ED, Lawand NB, Westlund KN, Willis WD. Pelvic visceral input into the nucleus gracilis is largely mediated by the post synaptic dorsal column pathway. J Neuorophysiol 1996;76:2675-90.

33. Al-Chaer ED, Westlund KN, Willis WD. Nucleus gracilis: an integrator for visceral and somatic information. J Neurophysiol 1997;78:521-7.

34. Shin HC, Chapin JK. Mapping the effects of motor cortex stimulation on somatosensory relay neurons in the rat thalamus. Direct responses and afferent modulation. Brain Res Bull 1990;24:257-65.

35. Yen CT, Honda CN, Jones EG. Electrophysiological study of spinothalamic inputs to ventrolateral and adjacent thalamic nuclei of the cat. J Neurophysiol 1991;66:1033-47.

36. Angyan L. Somatomotor and cardiorespiratory response to basal ganglia stimulation in cats. Physiol Behav 1994;56:167-173.

37. Benarroch EE, Stotz-Potter EH. Dysautonomia in fatal familial insomnia as indicator of the potential role of the thalamus in automatic control. Brain Pathol 1998;8:527-30. 
38. Newberry NR, Simmonds MA. The rat gracile nucleus in vitro: I. Evidence for the GABA-mediated depolarization of the dorsal column afferents. Brain Res 1984;303:41-9.

39. Newberry NR, Simmonds MA. The rat gracile nucleus in vitro: III. Unitary spike potentials and their conditioned inhibition. Brain Res 1984; 303:59-65.

40. Togashi H, Sakuma I, Yoshioka M, Kobayashi T, Yasuda H, Kitabatake A, et al. A central nervous system action of nitric oxide in blood pressure regulation. J Pharmacol Exp Ther 1992;262:343-7.

41. Zanzinger J, Czachurski J, Seller H. Effects of nitric oxide on sympathetic baroreflex transmission in the nucleus tractus solitarii and caudal ventrolateral medulla in cats. Neurosci Lett 1995;197:199-202.

42. Li WM, Sato A, Suzuki A. The inhibitory role of nitric oxide (NO) in the somatocardiac sympathetic C-reflex in anesthetized rats. Neurosci Res 1995;22:375-80.

43. Chen S, Ma SX. Effects of L-arginine-derived nitric oxide synthesis on cardiovascular responses to stimulus-evoked somatosympathetic reflexes in the gracile nucleus. Brain Res 2002;958:330-7.

44. Chen S, Ma SX. Nitric oxide on acupuncture (ST36)-induced depressor response in the gracile nucleus. $J$ Neurophysiol 2003;90:780-5.

45. Ma SX. An acupuncture analgesic/sympathoinhibitory pathway mediated by nitric oxide in the gracile-thalamic-tract. FASEB $J$ 2003;17: A1253.

46. Ma SX. A novel signal pathway: Nitric oxide mediates acupunctureinduced neuronal activity and analgesia in the dorsal medulla-thalamic tract. The First World Congress on Chinese Medicine 2003;95:A7.

47. Besson JM, Chaouch A. Periferal and spinal mechanisms of nociception. Physiol Res 1987;172:243-57.

48. Duggan AW, Morton CR. Tonic descending inhibition and spinal nociceptive transmission. Prog Brain Res 1988;77:193-211.

49. Fields HL, Basbaum AI. Brain stem control of spinal pain transmission neurons. Annu Rev Physiol 1978;40:193-221.

50. Clark FM, Proudfit HK. The projection of locus coeruleus neurons to the spinal cord in the rat determined by anterograde tracing combined with immunocytochemistry. Brain Res 1991;538:232-45.

51. Gebhart GF, Sandkuhler J, Thalhammer JG, Zimmermann M. Inhibition of spinal nociceptive information by stimulation in midbrain of the cat is blocked by lidocaine microinjected in nucleus raphe magnus and medullary reticular formation. J Neurophysiol 1983;50:1446-59.

52. Lee JH, Beitz AJ. Electroacupuncture modifies the expression of c-fos in the spinal cord induced by noxious stimulation. Brain Res 1992;577:8091.

53. Sun WY, Li XW, Luo ZC, Liu Y, Dun ZQ. Electroacupuncture at Huatuo Jiaji point inhibits the expression of Fos protein in rat spinal cord induced by traumatic pain. Acup Res 1996;21:60-4.

54. Lao L, Zhang G, Wei F, Berman BM, Ren K. Electroacupuncture attenuates behavioral hyperalgesia and selectively reduces spinal Fos protein expression in rats with persistent inflammation. J Pain 2001;2:111-7.

55. Kalra A, Urban MO, Sluka KA. Blockade of opioid receptors in rostral ventral medulla prevents antihyperalgesia produced by transcutaneous electrical nerve stimulation (TENS). J Pharmacol Exp Ther 2001;298: 257-63.

56. Takeshige C, Sato T, Mera T, Hisamitsu T, Fang J. Descending pain inhibitory system involved in acupuncture analgesia. Brain Res Bull 1992;29:617-34.

57. Takeshige $\mathrm{C}$, Sato $\mathrm{T}$, Komugi $\mathrm{H}$. Role of periaqueductal central gray in acupuncture anaesthesia. Acupunct Electrother Res 1980;5:323-37.

58. Souvannakitti L, Akasereenont P, Ketsa-ard K, Chotewuttakorn S, Thaworn A. Platelet serotonin in headache patients treated by new trend acupuncture. Proceedings of the 7th World Congress on Pain. 1993; Seattle, WA: IASP Press 429.

59. Wu J, Deng X. The mast cell biologically-active substances and electroacupuncture analgesic effect. Proceedings of the 7th World Congress on Pain 1993; Seattle, WA: IASP Press 429.

60. Molander C, Grant G. Laminar distribution and somatotopic organization of primary afferent fibers from hindlimb nerves in the dorsal horn. A study by transganglionic transport of horseradish peroxidase in the rat. Neuroscience 1986;19:297-312.

61. Molander C, Hongpaisan J, Persson JKE. Distribution of c-fos expressing dorsal horn neurons after electrical stimulation of low threshold sensory fibers in the chronically injured sciatic nerve. Brain Res 1994; 644:74-82.

62. Harper AA, Lawson SN. Electrical properties of rat dorsal root ganglion neurons with different peripheral nerve conduction velocities. J Physiol 1985;359:47-63.

63. Chiang CY, Chang CT, Chu HL, Yang LF. Peripheral afferent pathway for acupuncture analgesia. Sci Sin 1973;[B]XVI:210-7.

64. Andersson SA, Holmgren E. On acupuncture analgesia and the mechanism of pain. American Journal of Chinese Medicine 1975;3:311-34.

65. Kawakita K, Funakoshi M. Suppression of the jaw-opening reflex by conditioning $\alpha$-delta fiber stimulation and electroacupuncture in the rat. Exp Neurol 1982;78:461-5.

66. Levine JD, Gormley J, Fields HL. Observations on the analgesic effects of needle acupuncture. Pain 1976;2:149-59.

67. Pomeranz B, Cheng R. Suppression of noxious responses in single neurons of cat spinal cord by electroacupuncture and its reversal by the opiate antagonistnaloxone. Exp Neurol 1979;64:327-41.

68. Han J, Zhou Z, Xuan Y. Acupuncture has an analgesic effect in rabbits. Pain 1983;15:83-91.

69. Han JS, Xie GX. Dynorphin: important mediator for electroacupuncture analgesia in the spinal cord of the rabbit. Pain 1984;18:367-76.

70. Wang Q, Mao LM, Han JS. Diencephalon as a cardinal neural structure for mediating $2 \mathrm{~Hz}$ - but not $100 \mathrm{~Hz}$-electroacupuncture analgesia. Behav Brain Res 1990;37:148-56.

71. Han JS, Zhang M, Ren MF. The effect of spinal transection on acupuncture analgesia and morphine analgesia. Kexue Tongbao 1986;31:710-5.

72. Wang Q, Mao LM, Han JS. The role of periaqueductal gray in mediation of analgesia produced by different frequencies electroacupuncture stimulation in rats. International Journal of Neuroscience 1990;52: 167-72.

73. Han JS, Chen XH, Sun SL, Xu XJ, Yuan Y, Yan SC. Effect of low-and high-frequency TENS on metenkephalin-Arg Phe and dynorphin A immunoreactivity in human lumbar CSF. Pain 1991;47:295-8.

74. Zhang RX, Zhang G, Wang X, Berman B, Ren K, Lao L. The effects of electroacupuncture (EA) on persistent hyeralgesia and inflammationinduced Fos protein expression in rats: A parametric study. Society for Neurosci. 2001. The Traditional Chinese Medicine Alumni and Association (TCMA), Forum Edition, 2001 [abstract].

75. Gaw AC, Chang LW, Shaw LC. Efficacy of acupuncture on osteoarthritic pain. A controlled, double-blind study. N Engl J Med 1975; 293:375-8.

76. Godfrey CM, Morgan P. A controlled trial of the theory of acupuncture in musculoskeletal pain. J Rheumatol 1978;5:121-4.

77. Goddard G, Karibe H, McNeill C, Villafuerte E. Acupuncture and sham acupuncture reduce muscle pain in myofascial pain patients. $J$ Orofac Pain 2002;16:71-76.

78. Lewith GT, Machin D. On the evaluation of the clinical effects of acupuncture. Pain 1983;16:111-27.

79. Richardson PH, Vincent CA. Acupuncture for the treatment of pain: a review of evaluative research. Pain 1986;24:15-40.

80. Margolin A, Kleber HD, Avants SK, Konefal J, Gawin F, Stark E, et al. Acupuncture for the treatment of cocaine addiction: a randomized controlled trial. J Am Med Assoc 2002;287:55-63.

81. Bullock ML, Kiresuk TJ, Sherman RE, Lenz SK, Culliton PD, Boucher TA, et al. A large randomized placebo controlled study of auricular acupuncture for alcohol dependence. J Subst Abuse Treat 2002;22:71-7.

82. Vincent C, Lewith G. Placebo controls for acupuncture studies. $J$ Roy Soc Med 1995;88:199-202.

83. Park J, White A, Lee H, Ernst E. Development of a New Sham Needle. Acup Med 1999; 17:110.

84. Park J, White A, Stevinson C, Ernst E, James M. Validating a new nonpenetrating sham acupuncture device: two randomised controlled trials. Acup Med 2002;20:168.

85. Streitberger K, Kleinhenz J. Introducing an placebo needle into acupuncture research. Lancet 1998;352:364-5.

86. Araujo MS. Does the choice of placebo determine the results of clinical studies on acupuncture? A meta-analysis of 100 clinical trials. Forsch Komplementarmed 1998;5 (Suppl 1):8-11. 


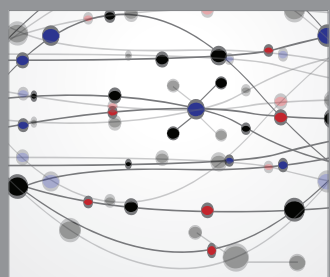

The Scientific World Journal
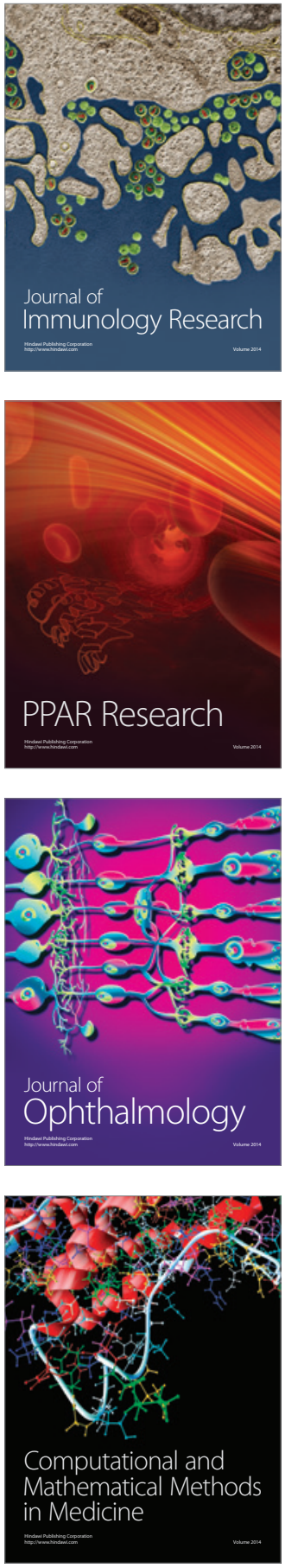

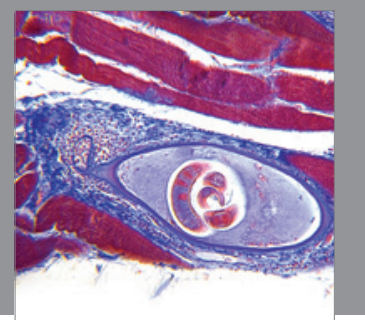

Gastroenterology

Research and Practice
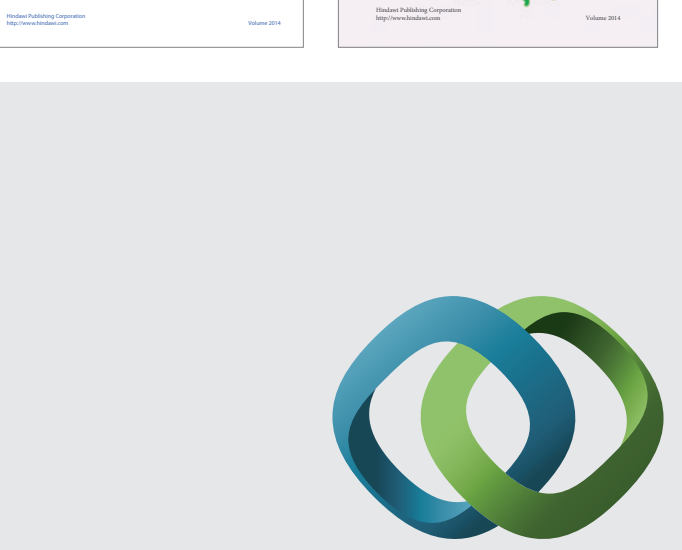

\section{Hindawi}

Submit your manuscripts at

http://www.hindawi.com
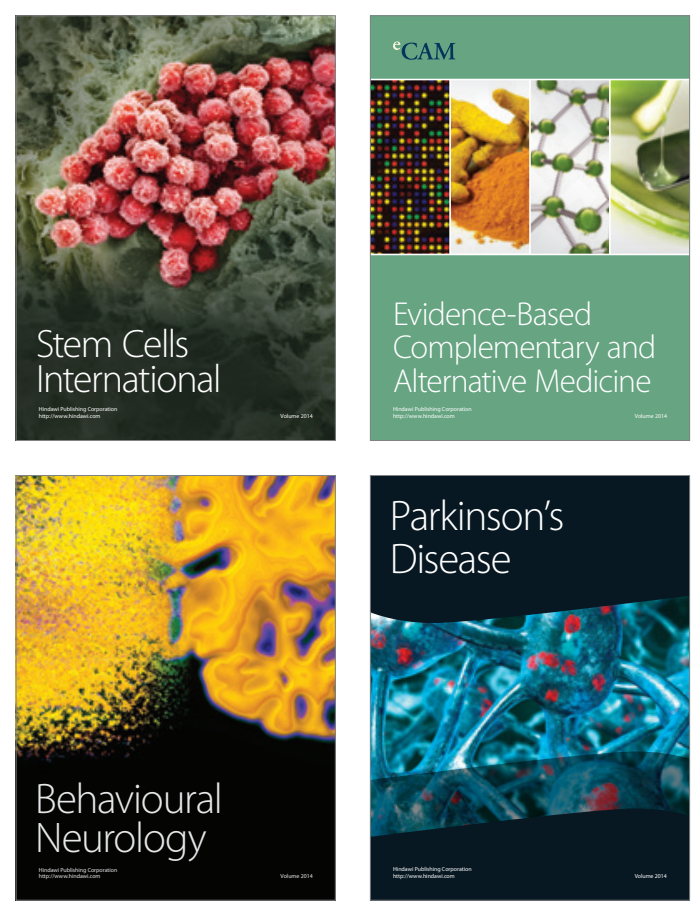

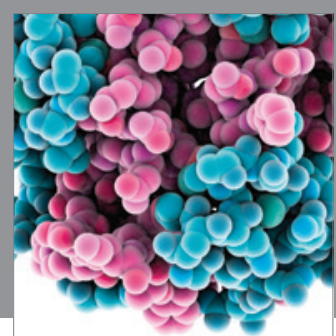

Journal of
Diabetes Research

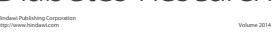

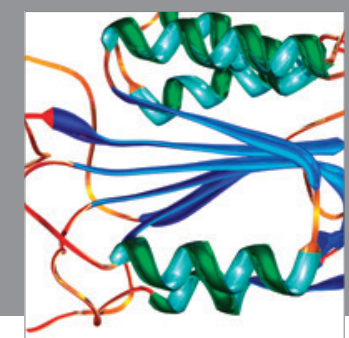

Disease Markers
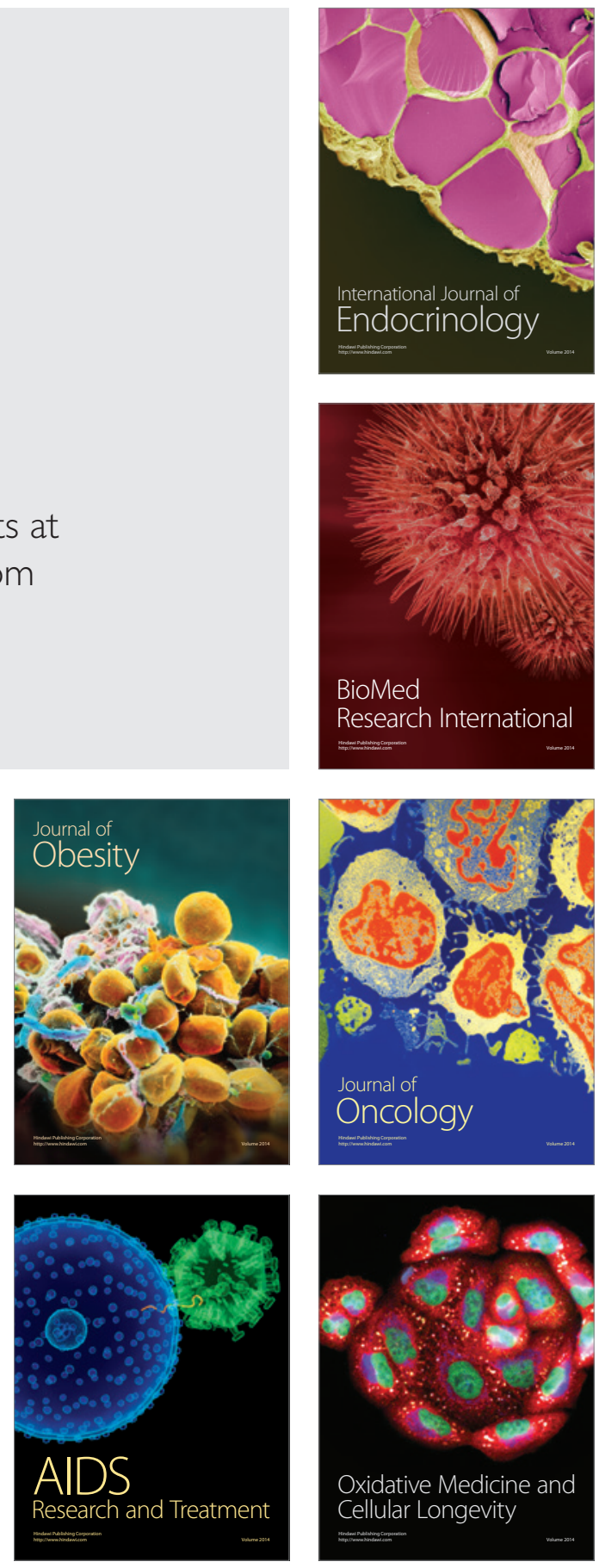